\title{
"THE CHILD AND THE TOY: AN IMPORTANT RELATIONSHIP"
}

Eliana Jany Barbanti*

\begin{abstract}
Investigating the importance of toy in child development from a functional, psycho-social and social viewpoint is the purpose of this paper. It has been noticed that through toy, more than through any other activity, the child learns to manipulate and control his objects. He deals with psychological problems when he lives over through toys the problems he has been

faced with in reality, and learns about social relations when he realizes that he must adjust himself to others if he wants to share his toys. There is a consensus that toy is a means of preparing a child for future occupations. This approach is shown through Cross-Cultural Analysis of games and the Conflict of Enculturement within social aspects of games and play.
\end{abstract}

UNITERMS: Children's plays. Play activities

\section{1 - INTRODUCTION}

Is there actually an important relationship between child and toy? What is the meaning of such relationship? Answering these questions in this context is considering toy not only as an object for children to play with, but also as entertainment, play.

Although for many authors the terms " play" and " games" are often interchangeable, they differ in meaning.

"Generally speaking, play refers to small children's activities, characterized by absolute lack of set rules, exception made to those personally imposed, by free involvement of fantasy and by the absence of objects not pertaining to the activity itself. 'Games", on the other hand, have rules, are competitive and characterized by the demand for making proper use of the objects of the activity, that is, in the manner for which they were built and not as imagination wills. Games are also frequently characterized by an object or purpose other than the game itself - winning, for instance" Bettelheim, 1988.

In order to answer the introductory questions satisfactorily we shall analyze the value of toy, its functional, psycho-social and social aspects and its involvement with children. 


\section{2 - THE VALUe Of TOY}

According to Bettelheim (1988) " toys have always represented inventions and reflected the symbols of society's technological progress" The author states that today's cars, lorries, airplanes and spaceships play the same role in our children's play as did the carriage in Ancient India or Greece. According to the author the popularity of assembling toys, planes, walkie-talkies, moon jeeps and so on, show a child'd interest in objects that are pieces of workmanship in adult life. It is very important for them that parents share feelings of pleasure, playing with these toys. In this sense, the author reports that for children, the pleasure is drawn, in the first place, from fantasies about being at that very moment, great pilots, musicians, paintors, inventors, whereas parent's enthusiasm tends to be based upon projections for the child's future.

This idea is shared by Dias Pacheco (1986) as for play expression differences between adults and children. Besides, the author deeply analyzes the matter, drawing a comparison between child's development and toy. She draws a line from the child's first year to adolescence and reports motor-sensory experiences resulting from actions on goals he is surrounded by during the different stages in child development. - Hide-and-seek, Drop-a-handkerchief, Button-button-who's-got-a-button, Blindman's buff, key rings, the child's body itself, cushions, pan cupboards, water, earth, sand, doll, cloth or plush toy pets, containers that he can empty or fill, the house in a child's drawing, story books, making believe he is a parent or a doctor, intellectual games now with rules, are references made by the author in her comparison between development and play.

She infers that " child play'enriches mood, magic, freedom, power, smartness and aggressivity."

Thus, through toy more than through any other activity, the child learns to manipulate and control his objecțs; when he builds with blocks he deals with psychological problems, he lives over through toys problems he has been faced with in reality, just as he imposes to his toy pet a painful experience he himself has known. And he learns about social relationship when he starts understanding that he must adjust himself to others if he wishes to share his toys with them.

Therefore, there is a functional and a psycho-social aspect connected to play. Analysis of such process follows.

\section{3 - FUNCTIONAL AND PSYCHO-SOCIAL ASPECT OF PLAY}

In the first place, children join play because it is something pleasant. This is so obvious, it seems unecessary to mention. To authors like Martens (1981) such pleasure derives from the activity itself; he describes it as a " flow" where activity is neither monotonous nor does it cause stress which leads to anxiety. (Figure 1)

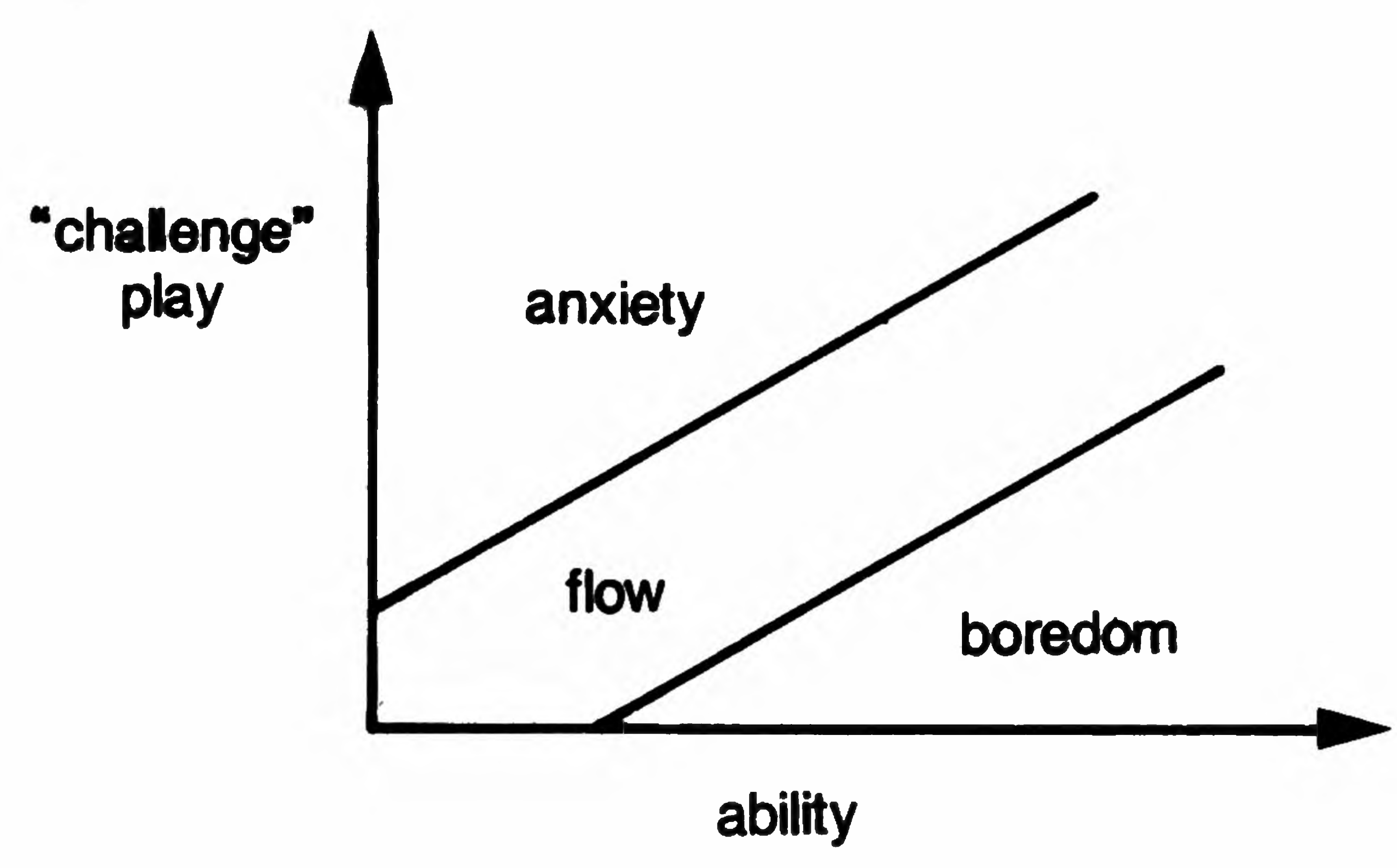

Figure 1

Children like to feel that their body works well: Pavlov refers to this functional aspect as " muscular happiness" In this sense it id understood that while children exercise their bodies, obtaining control over them as they run and hop, they feel such exuberance that they often fail to quiet down, and express through loud shrieks their happiness for what their bodies can do, unaware of the actual reason. Pleasure drawn from the fact that our body and mind are sound and serving us well is the foundation to the feeling of well being. The solitary game provides us with satisfaction drawn from the experience of working well, but as we play against others, we discover another great satisfaction of life which is, interaction with fellow beings. Bettelheim (1988) emphasises that the real foundation for these experiences is created through 
play. A baby is delighted when he plays with his parents but in the long run, he will not feel pleasure until his happiness is ratified by them.

The same author states that " playing is very important because besides stimulating the child's intellectual development, it teaches, without his noticing, the fundamental habits for such growth, as perseverance, so important in all learning. " Further important points are stressed by the author: in play and through it, the child exercises mental procedures; the development of speech is also expedited if the adult participates while parent and child play together. In an attempt to understand Einstein's words, the author states that children overcome the frustrating feeling of living in a world they cannot rule, creating a more understanding world which they can comprehend. They do so in a way that is convenient just for themselves and that they alone know. Thus, these authors show in their observations, the importance of play in the development of logical constructions and shaping of one's self image. Perhaps, however, play's major importance is found in the child's immediate pleasure, which is extended to pleasure of living. Dias Pacheco mentions this immediate pleasure, when she refers to play expressions and their different meanings for children and adults, where the child lives and represents the outside world according to his inner world. Play allows a child to solve in a symbolic way, problems not solved in the past and to face current matters in a straight forward or symbolic way. There is a consensus that toy is a way of preparing a child for future occupations. This approach will be shown through " Cross-Cultural Analysis of Games and the Enculturation Conflict within social aspects of games and play"

There are therefore, the psychological and unsonscious aspects of play, its functions in the development of motor and cognitive skills and the sociological aspect which we will now study.

\section{4 - SOCIOLOGICAL ASPECTS OF GAMES AND PLAY}

The process of socialization is a learning and reproducing process of social values. Play and games are situations in which an important learning takes place. The learning of child socialization is one of them. They are drills for the accomplishment of ruling the external world.

According to Bettelheim (1988) many languages have just one word for something English express in two nouns: " play" and " game" and just one verb for both activities - " to play" In English you can say: "We play at playing, and we play a game" As it has already been stated, play refers to a more primitive level and games require a more mature level of comprehension. Games with their definite structure and competitive aspects, are usually closer to the adult way of spending time and consequently, evoke a more immediate empathy in adults.

After we have understood the meaning of play and games through these definitions, we must also stress social skills which arise from games and as the outcome of given specific styles of play. In this sense, another important learning takes place: the child learns his social role. Therefore, there are sexual differences in games and play which we will now see.

\section{1 - SEXUAL DIFERENCES IN GAMES AND PLAY}

Lever (1978) states that there are sexual differences in play. It may be on account of parents' expectations towards their children or the way in which they are treated. Boys are expected to be daring, independent, confident and emottionally controlled, Girls on the other hand, are expected to be sweet, obedient, refined, considerate. Children are therefore trated in different ways.

Sutton-Smith (1979) stresses that there might be some such evidence as mothers play more frequently and socially with girls. although this play is not so frequent, it is possible that girls imitate mothers directive role, as well as their role in the play. 
Apparent "negligence" towards boys plus mothers expectations convey that they should play more independently, suggesting that boys get an involvement wider than that of sheer players, but that they are the ones who control the play. Fathers as opposed to mothers in play situations, prefer to provide their children with more stimulating and exciting activities.

Lever (1978) furthermore states that boys' play is more complex than girls Mentioning a well known example, in boys play there are a few elementary theories such as leadership and chase, catch and find, which are endlessly interlaced in more complex games. Sutton-Smith has called this, game sintax.

Similarly, girls' activities involving dolls, in an anticipated process of socialization are meant to prepare girls for future roles as mothers and housewives. The author says that boys' games particularly emphasize:

- body strength and body contact

- continuous flow of activity body

- motor activity involving the whole activities

- use of wider spaces and outdoor

- fantasied or real conflict between groups or teams

- success accomplishment through active interference with another player

- clear-cut results neatly showing winners and losers

- play in large groups

- longer lasting games

- larger groups with participation of different age ranges

As opposed to this, the authors analyses characteristics of girls games:

- sequence order rhythm

- choral activity, songs, music and play

- multiple and well defined stages of

- indirect competition movement

- variety of rules established for every body

- partial solicitation of parts of the

- individual rather than group competition

According to the author such characteristics prepare boys to play within groups and complex constitutions of society, while girls are prepared for more restrict or family roles of relationship within smaller groups.

\section{2 - CROSS-CULTURAL STUDY OF GAMES}

Callois (1961) defines game as " any form of competitive play in which the result is determined by physical skill, strategy or chance applied individually or not." There are three categories of game: which:

Physical skill, chance and strategy in

Physical skill games are the ones whose result is established by participants motor activities (running, running at the ring, etc.)

Chance games are the ones whose result is determined by guessing or given external devices as dice, roulette (bingo, lottery, etc.)

Strategy games are the ones whose result is determined by rational options (draught, chess, puzzles, etc.)

\section{3 - THE ENCULTURATION CONFLICT THEORY OF GAMES}

According to Robert and Sulton-Smith (1963) the hypothesis of Enculturation Conflict states that practices carried out during childhood lead to conflict and drive to a curiosity towards acting (as expressive models., e.g., games). Involvement in these expressive models takes place because such microscopic acting reduces the complexities of the model to a cognitive and emotional comprehension and because of the success the child might experiment while performing.

This involvement on the other hand has an enculturation value, for the participant may learn about winning cognitive and emotional aspects in a safer way. Such success increases self confidence. Thus, they can work the pressions of achievement in a complete scale of cultural participation. Therefore, the model has a general cultural function of contributing for the learning and adjustment of people who must keep a high level of achievement. 


\section{MODEL OF ENCULTURATION CONFLICT BY \\ ROBERTS \$ SUTTON-SMITH}
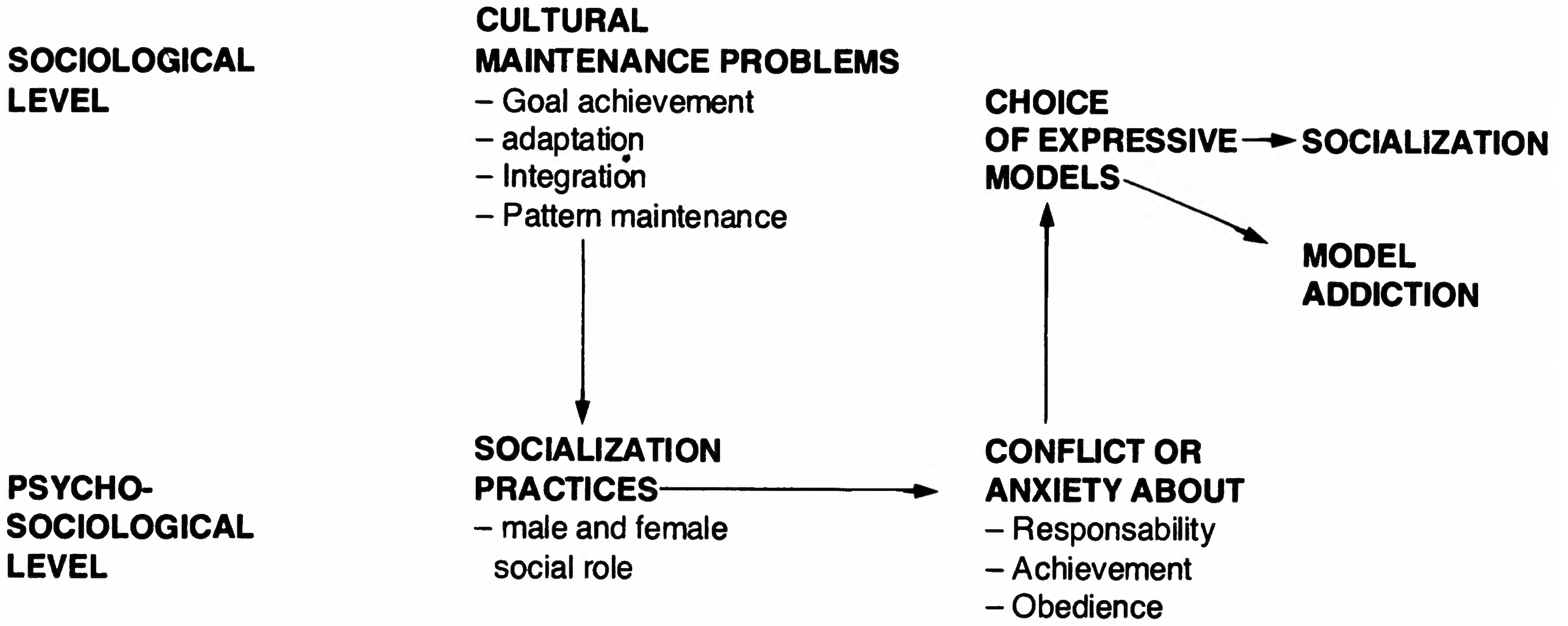

PHYSICAL SKILL GAMES

$\rightarrow$ COMMAND OF SOCIAL SYSTEM

CHANCE GAMES

$\rightarrow$ SUPERNATURAL

STRATEGY GAMES

$\rightarrow \quad$ ME AND THE ENVIROMENT

\section{CONCLUSION}

If we understand the importance of play we will agree that besides being a pleasant activity it is a serious and significative occupation. With great pleasure we provide toys and games for children, encouraging and helping them to make use of such things, and minding that they play with other children. Play changes as children grow in comprehension and different problems start to occupy their mind.

Trough play they begin to realise how things work: what may or may not be done with the objects and how, and the first whys and why nots. By playing with other children they learn that there are rules of chance and probability, as well as rules of behaviour that must be complied with if others are expected to play with them. Therefore, for all . these reasons and many more that have been mentioned in this article we can assure that THERE ACTUALLY IS A VERY IMPORTANT RELATIONSHIP BETWEEN CHILD AND TOY.

The references are found in the article in Portuguese.

* Teacher of the Sports Practice Center USP 